\title{
Respiratory muscle strength during continuous ambulatory peritoneal dialysis (CAPD)
}

\author{
N.M. Siafakas, T. Argyrakopoulos, K Andreopoulos, \\ G. Tsoukalas, N. Tzanakis, D. Bouros
}

Respiratory muscle strength during continuous ambulatory peritoneal dialysis (CAPD). N.M. Siafakas, T. Argyrakopoulos, K. Andreopoulos, G. Tsoukalas, N. Tzanakis, D. Bouros. CERS Journals Ltd 1995.

ABSTRACT: The purpose of this study was to investigate the effect of chronic renal failure (CRF) and continuous ambulatory peritoneal dialysis (CAPD) on respiratory muscle function. Global respiratory muscle strength was assessed by measuring mouth pressures during maximum static inspiration (PImax) near residual volume (RV) and expiration (PEmax) near total lung capacity (TLC), in 26 patients.

Maximum pressures, spirometry and lung volumes were measured before dialysis, $4 \mathrm{~h}$ after the administration of $2 \boldsymbol{l}$ of dialysate into the peritoneal cavity, and just after the next drainage. In addition, biochemical indices (urea, creatinine, sodium, potassium, calcium and phosphorus) and haematological indices (haemoglobin (Hb) and haematocrit (Hct)) were measured once before the treatment.

The results showed that mean PImax and Pemax were normal, with a very wide range between patients, before CAPD. However, seven patients $(27 \%)$ showed a PImax of $<75 \%$ predicted (pred) and eight $(31 \%)$ a Pemax $<75 \%$ pred. Maximal pressures decreased significantly during CAPD and increased again after the drainage of fluid. Similarly, lung volumes were within the normal range before and decreased significantly during CAPD. The forced expiratory volume in one second to forced vital capacity $\left(\mathrm{FEV}_{1} / \mathrm{FVC}\right)$ ratio did not change.

We conclude that respiratory muscle strength was preserved in the majority of the patients with chronic renal failure treated with CAPD. During CAPD, lung volumes and respiratory muscle function were decreased, demonstrating an effect of the abdominal cavity on the mechanics of the respiratory system. However, the decrease in the maximum pressures was less than $20 \%$, indicating that CAPD is a safe procedure in patients without pre-existing pulmonary disease or uraemic pulmonary complications. Respiratory muscle strength increased immediately after the drainage of fluid.

Eur Respir J., 1995, 8, 109-113.
Depts of Thoracic Medicine, University Hospital, University of Crete Medical School, Heraklion, Crete and Evangelismos Hospital, Athens, Greece.

Correspondence: N.M. Siafakas

Dept of Thoracic Medicine

University Hospital of Crete

University of Crete

School of Medicine

P.O. Box. 1352

Heraklion

71110 Crete

Greece

Keywords: Abdominal cavity continuous ambulatory peritoneal dialysis maximal inspiratory and expiratory pressures

mechanics of breathing

renal failure

respiratory muscles

Received: March 221994

Accepted after revision August 241994

Preliminary results of this study were presented at the Annual Meeting of the American Thoracic Society 1992, Miami, Florida. and at the 2nd Annual Meeting of the European Respiratory Society, 1992, Vienna, Austria.
It is well-known that a number of respiratory complications occur in patients with chronic renal failure (CRF). Common expressions of the uraemic lung are pulmonary oedema, fibrosis, pulmonary hypertension, haemosiderosis and pleural effusion [1-4]. Patients with chronic renal failure are often treated with continuous ambulatory peritoneal dialysis (CAPD) [5]. This technique is based on the fact that small molecular weight solutes reach complete equilibration with peritoneal fluid. Thus, the patient exchanges 1.5-3.0 $l$ and is able to maintain adequate removal of solutes and water. The advantages of CAPD in comparison to haemodialysis are that it requires no machinery; patients are not dependent on nurses, or other personnel, and have better mobility; there is better control of blood pressure and blood glucose, and less cardio-vascular stress; and it is less expensive.

CAPD requires the administration of approximately $2 l$ of fluid into the abdomen [5]. It is likely that this treatment could affect the mechanics of the abdominal cavity, which is a significant part of the respiratory pump. In addition, the administration of fluid into the peritoneal cavity may affect the function of the respiratory muscles, due to changes in their force-length relationship. The few studies that have investigated respiratory muscle function during CAPD have been conducted on a small number of patients, and have produced controversial results [6-9]. Gomez-Fernandez et al. [6] studied 10 patients and showed an increase in maximum inspiratory pressure (Pimax) during CAPD. PREZANT et al. [7] showed similar results after the infusion of $3 l$ into the peritoneal cavity. In contrast, Bush et al. [8] measuring PImax and diaphragmatic pressure (Pdi) in 10 patients, found no difference in the pressures with the abdomen empty or full, in the sitting position.

In order to investigate the effect on respiratory muscle strength, 26 patients were studied before, during and immediately after the administration of $2 l$ of fluid into the peritoneal cavity. 


\section{Material and methods}

We studied 26 consecutive patients with chronic renal failure treated with CAPD. Exclusion criteria to this study were recent or chronic lung or chest wall diseases, renal diseases that affected the lungs or the muscles (collagen disorders), and the use of drugs that influenced respiratory muscle function, such as steroids or cyclophosphamide. Pleural effusions were excluded by clinical examination and routine chest radiography (posteroanterior and lateral). All patients were nonsmokers or ex-smokers (having given up smoking at least one year before this study), and none had evidence of peritonitis, at least 3 weeks before the measurements. All patients were ambulatory and in stable clinical condition, without signs of fluid retention or other symptoms of severe uraemia.

On the day of the study, blood was taken for biochemical profile (urea $(\mathrm{U})$, creatinine $(\mathrm{Cr})$, sodium $(\mathrm{Na})$, potassium $(\mathrm{K})$, calcium $(\mathrm{Ca})$, phosphorus $(\mathrm{P})$, and full blood count (haematocrit $(\mathrm{Hct})$ and haemoglobin $(\mathrm{Hb})$ ) before the CAPD treatment.

Lung function tests and maximum static inspiratory (PImax) and expiratory (Pemax) pressures were measured in the seated position before dialysis, $4 \mathrm{~h}$ after the administration of $2 l$ of fluid into the peritoneal cavity (4.25 $\mathrm{g} \cdot \mathrm{dl}^{-1}$ dextrose solution: 4.25 Dianeal) and just after the drainage. It is known that $4 \mathrm{~h}$ after the admission of fluid the abdominal cavity is at its "maximum fullness" [10]. The volume of the fluid drained was measured.

Total lung capacity (TLC), residual volume (RV), and functional residual capacity (FRC), were measured using the helium dilution technique (P.K. Morgan, UK). Forced expiratory volume in one second $\left(\mathrm{FEV}_{1}\right)$ and forced vital capacity (FVC) were measured using the same apparatus and the $\mathrm{FEV}_{1} / \mathrm{FVC}$ ratio was calculated. All lung volumes were corrected to body temperature and pressure saturated with water vapour (BTPS) and expressed as a percentage of predicted values (\% pred) [11].

Global respiratory muscle strength was assessed by measuring PImax and Pemax according to the method of Black and Hyatт [12]. Pimax was measured near RV, and Pemax near TLC. Both manometers used to measure the maximum pressures (Maxant, Paris, France) had two needles, one of which rested at the maximum pressure produced during the effort, enabling us to read the pressure with accuracy. Efforts were considered satisfactory when maximum pressure was maintained for at least 1 $\mathrm{s}$. The patients practised the manoeuvres several times, and when the variability was less then 5\% the highest value was used for calculations. Details of the method used have been described previously [13]. Pressures without positive or negative signs were expressed as a percentage of predicted values taken from BLACK and Hyatт [12] and in kilopascals. The protocol was approved by the Ethics Committee of the hospital.

Statistical analysis was carried out using the student's paired t-test to evaluate statistically significant differences in the mean values between the data measured before, during and after CAPD. In addition, the differences in the mean values were estimated by the two-way analysis of variance (ANOVA) test. The least squares method was used to calculate linear relationships. A probability (p) value less than 0.05 was considered to indicate statistical significance. Data are shown as mean values \pm 1 standard error (SEM).

\section{Results}

Anthropometric data of the patients, mean duration of chronic renal failure, mean duration of CAPD, mean volume of the drained fluid, and mean values of the measured biochemical and haematological parameters are shown in table 1 . The mean values of sodiumand potassium were within the normal range, calcium and phosphorus were marginally abnormal, but urea and creatinine were almost tenfold higher than normal levels (table 1). The mean Hct and $\mathrm{Hb}$ values were significantly lower than the lower normal values.

The mean values of the lung indices were within the normal range (80-120\% pred) before CAPD. Figure 1 shows TLC and RV before, during and after CAPD. All the respiratory parameters decreased during CAPD and this change was statistically significant $(\mathrm{p}<0.05)$, but increased to pre-CAPD level after treatment $(p<0.05)$. However, the $\mathrm{FEV}_{1} / \mathrm{FVC}$ ratio did not change $(\mathrm{p}>0.23)$.

The mean value of PImax ( \pm SEM) was $7.62 \pm 0.6 \mathrm{kPa}$ before, $6.2 \pm 0.56 \mathrm{kPa}$ during, and $7.2 \pm 0.63 \mathrm{kPa}$ after

Table 1. - Mean values of the anthropometric data, the duration of CRF, CAPD, volume of drained fluid, and biochemical and haematological parameters

\begin{tabular}{|c|c|c|}
\hline Parameter & Measurements & $\begin{array}{l}\text { Normal } \\
\text { range }\end{array}$ \\
\hline Age yrs & $\begin{array}{l}52 \pm 3 \\
(15-76)\end{array}$ & \\
\hline Height $\mathrm{cm}$ & $\begin{array}{c}16 \pm 2 \\
(145-182)\end{array}$ & \\
\hline Weight $\mathrm{Kg}$ & $\begin{array}{l}68 \pm 2 \\
(50-104)\end{array}$ & \\
\hline$\%$ IBW & $\begin{array}{l}114 \pm 5 \\
(79-158)\end{array}$ & \\
\hline Duration of illness months & $\begin{array}{c}70 \pm 10.7 \\
(9-216)\end{array}$ & \\
\hline Duration of CAPD months & $\begin{array}{r}15.7 \pm 1.9 \\
(2-36)\end{array}$ & \\
\hline Volume of drained fluid $l$ & $\begin{array}{r}3.35 \pm 0.07 \\
(2.6-3.7)\end{array}$ & \\
\hline Urea $\mathrm{mmol} \cdot l^{-1}$ & $\begin{array}{c}61 \pm 3.1 \\
(28.6-107.1)\end{array}$ & $2.2-8.0$ \\
\hline Creatinine $\mathrm{mmol} \cdot l^{-1}$ & $\begin{array}{l}1091 \pm 55 \\
(555-1618)\end{array}$ & $<140$ \\
\hline Sodium $\mathrm{mmol} \cdot l^{-1}$ & $\begin{array}{l}135 \pm 0.7 \\
(130-146)\end{array}$ & $136-145$ \\
\hline Potassium $\mathrm{mmol} \cdot l^{-1}$ & $\begin{array}{c}4.8 \pm 0.09 \\
(4.1-5.7)\end{array}$ & $3.5-5$ \\
\hline Calcium $\mathrm{mmol} \cdot l^{-1}$ & $\begin{array}{c}2.05 \pm 0.02 \\
(1.85-2.25)\end{array}$ & $2.25-2.75$ \\
\hline Phosphorus $\mathrm{mmol} \cdot l^{-1}$ & $\begin{array}{c}1.58 \pm 0.03 \\
(1.29-1.84)\end{array}$ & $0.9-1.45$ \\
\hline Haematocrit Hct\% & $\begin{array}{c}26.3 \pm 0.98 \\
(19-36)\end{array}$ & $\begin{array}{l}M=47 \pm 5 \\
F=42 \pm 5\end{array}$ \\
\hline Haemoglobin $\mathrm{g} \cdot \mathrm{dl}^{-1}$ & $\begin{array}{r}8.72 \pm 0.24 \\
\quad(7-12.3)\end{array}$ & $\begin{array}{l}M=14-18 \\
F=12-16\end{array}$ \\
\hline
\end{tabular}

Data are presented as mean \pm SEM, and range in parenthesis $\mathrm{M}$ : male; IBW: ideal body weight; F: female; CRF: chronic renal failure; CAPD: continuous ambulatory peritoneal dialysis. 


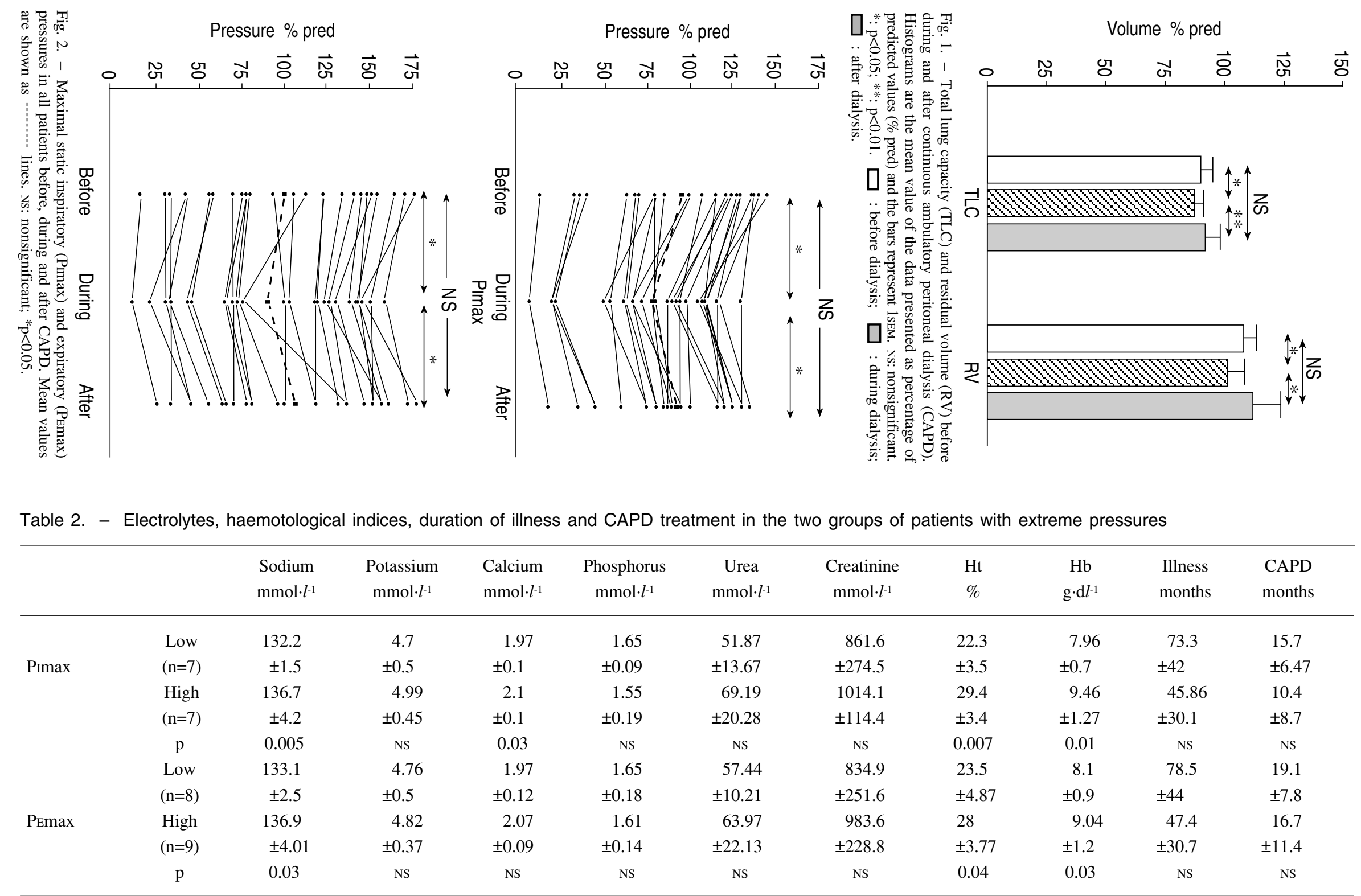

Data are presented as mean \pm SD. Low: $\leq 75 \%$ pred; High: $\geq 125 \%$ pred; Ns: nonsignificant; PImax: maximal inspiratory pressure; PEmax: maximal expiratory pressure; Ht: haematocrit; $\mathrm{Hb}$ : haemoglobin; CAPD: continuous ambulatory peritoneal dialysis. 
CAPD. The mean value of Pemax was $11.2 \pm 1.24 \mathrm{kPa}$ before, $10 \pm 1.1 \mathrm{kPa}$ during, and $11.8 \pm 1.2 \mathrm{kPa}$ after CAPD. These changes were statistically significant $(\mathrm{p}<0.05)$, between the values before or after CAPD and those during CAPD. Figure 2 shows PImax and Pemax in all patients as a percentage of the predicted value and the mean value of the group, before, during and after CAPD.

Although, the mean values of PImax and PEmax before CAPD were within the normal range, seven patients had a value of PImax $<75 \%$ pred and eight a Pemax $<75 \%$ pred (fig. 2). In addition seven patients had a Pimax $>125 \%$ pred and nine a Pemax $>125 \%$ pred (fig. 2). Electrolytes, haematological indices, duration of illness, and duration of CAPD in the two groups of patients with extreme pressures are shown in table 2.

Statistically significant differences in the mean values were found in sodium, calcium, haematocrit and haemoglobin (table 2). Furthermore, no relationship was found between the maximum pressures (Pimax, Pemax) measured before CAPD and the duration of renal failure, or the duration of CAPD, or the renal function indices, e.g. urea and creatinine.

\section{Discussion}

We undertook this study to investigate respiratory muscle strength in CRF during CAPD treatment in 26 patients. Our results showed that the mean global respiratory muscle strength was within the predicted normal range before CAPD, but that both expiratory and inspiratory maximum pressures decreased significantly during CAPD with the abdominal cavity full of fluid. Both pressures increased up to the pre-CAPD level just after the drainage of the fluid.

Although it has been reported that patients with CRF treated by haemodialysis showed an impairment of respiratory muscle strength [14], our results showed that this is not true for patients treated by CAPD. However, seven patients $(27 \%)$ showed a low PImax before CAPD and eight patients $(31 \%)$ a low PEmax. These patients showed a lower value of sodium, calcium, haematocrit and haemoglobin in comparison to those with higher pressures. These results may be interpreted as demonstrating a relationship between respiratory muscle strength and the general condition of the patients, as has been seen in malnourished subjects [15].

Expiratory muscle strength (PEmax) during CAPD was assessed only in one other study, reported by BusH and co-workers [8]. Although the changes in Pemax in this study did not reach statistically significant levels, a trend was apparent showing a decrease in Pemax during CAPD. Our results demonstrated that Pemax decreased when the abdomen was full of fluid. This finding could be interpreted as the consequence of the administration of fluid into the peritoneal cavity, displacing the abdominal wall outwards and lengthening the abdominal muscles. Therefore, these muscles were working under less advantageous conditions when the abdomen was full. This was reversed when the fluid was drained from the abdominal cavity, supporting the argument that the mechanics of the cavity change when it is full of fluid and demonstrating the importance of the abdominal cavity in the function of the respiratory muscles.

Maximum inspiratory pressure has been measured in three previous studies during CAPD. Bush and coworkers studied 10 patients [8], GOMEZ-FERNANDEZ et al. [6] also 10, and PREZANT et al. [7] six patients. Following the introduction of $2 l$ of fluid into the peritoneal cavity, the above studies reported no significant change in PImax. The results of BusH and co-workers [8] showed a decrease in PImax with the abdomen full, but this was not statistically significant. The other two studies showed an increase in PImax, which was not significant, during CAPD $[6,7]$.

Our results showed that PImax, measured in 26 patients, $4 \mathrm{~h}$ after the administration of $2 l$ of fluid into the abdominal cavity decreased significantly. There are a number of possible explanations for the above differences. Firstly, the small number of patients that have been investigated in the previous three studies. Secondly, methodological differences concerning the timing of the measurements of PImax during the CAPD. We made our measurements $4 \mathrm{~h}$ after the administration of dialysate, because we aimed to investigate the behaviour of the abdominal cavity at its maximum "fullness" just before the next drainage. This is in accordance with our finding that the mean volume of the drained fluid was larger than $3 l(3.35 l)$. Thirdly, PreZANT et al. [7] measured PImax at FRC, whereas, we measured PImax near RV, according to the original description of the method by BlaCK and Hyatt [7]. In addition, GoMEZ-FERNANDEZ et al. [6], in order to explain their findings, implied that the infusion of $2 l$ of fluid into the peritoneal cavity improves diaphragmatic contractility due to changes in the electrolytes or other "uraemic toxins". However, they measured Pimax immediately after the administration of dialysate. It is most unlikely that a significant change in "toxins" occured so soon to be the cause of the improvement of diaphragmatic contractility. Our results argue against this hypothesis, since they show that the mean PImax was $97 \%$ pred before CAPD with "all the toxins" in the patients body.

Although, PREZANT et al. [7] showed no significant change in PImax following the addition of $2 l$ of fluid, they demonstrated an increase in Pimax after $3 l$ of fluid was instilled into the abdomen. They measured Pimax in six patients and also maximum diaphragmatic pressure (Pdimax) in three. The investigators suggested that the diaphragm adapts to a new force-length relationship to compensate for the chronic changes (lengthening) in its resting length due to CAPD [8]. However, even though they showed a significant increase in the length of the diaphragm using a radiographic technique with the instillation of 2 and $3 l$ of fluid, they found a significant increase in Pimax only when $3 l$ of dialysate was admitted into the abdominal cavity. In our study, PImax was measured near RV and not at FRC as in the study by PREZANT et al. [7]. It is well-known that at RV the zone of apposition of the diaphragm to the lateral chest wall is greater than that at FRC. Thus, we would suggest that fluid introduced into the abdomen may affect the 
mechanics of the diaphragm and/or the thoracic cavity to a greater extent at RV than at FRC.

Furthermore, we made our measurements $4 \mathrm{~h}$ after the administration of the dialysate, when the abdominal cavity was at its maximum "fullness" due to the accumulation of at least $3 l$ of fluid (table 1). Therefore, another possible explanation for our results could be that we have measured Pimax at a less advantageous portion of the force-length relationship of the diaphragm than the portion at which PREZANT et al. [7] made theirs. In other words, a significant lengthening of the diaphragm due to measurements made at RV, and the "fullness" of the abdomen, made the diaphragm operate at the descending part of the forcelength relationship beyond its optimal length, and, thus, at a mechanical disadvantage to produce maximum pressure.

In addition, in the seated posture, the administration of fluid into the peritoneal cavity is more likely to cause an outward displacement of the abdominal wall rather than an upward displacement of the diaphragm at RV due to gravitational forces. This may be followed by a similar outward displacement of the rib cage and stretching of the diaphragm. However, during the RV manoeuvres, due to the increased compliance of the abdominal contents (fluid), the diaphragm stretched even more, may be substantially beyond its optimum length, and, thus, its force-generating capability is impaired. Thus, the combination of the effects of the zone of apposition and that of the extreme lengthening of the diaphragm during CAPD, is an attractive hypothesis.

We did not measure abdominal and rib cage diameters or the length of the diaphragm with X-ray methods, but the volume of the drained fluid measured immediately after the pressure measurements support this explanation. In agreement with this hypothesis, we found that the PImax increased towards its pre-CAPD values immediately after the fluid had been drained from the abdominal cavity.

Our results show that the mean values of the spirometric indices were within the normal range before CAPD and showed a small but significant decrease during CAPD. These results are in agreement with those reported by other investigators [6-8]. All spirometric parameters increased after CAPD.

Our results are in accordance with those reported after an acute change in abdominal volume by withdrawing large volumes of ascitic fluid [16]. ABELMANN et al. [16] showed a significant improvement in TLC after abdominal paracentesis in ascitis. In contrast, during chronic increase of abdominal volume, as seen in pregnancy, maximum pressures did not change $[17,18]$. However, our results showed an effect on respiratory muscle strength after an acute alteration in abdominal volume during CAPD.

Although, we demonstrate a significant decrease in the maximal pressures during CAPD, this decrease was of the order of $20 \%$ for Pimax and $10 \%$ for Pemax. Thus, it is obvious that the respiratory muscles were able to produce significant pressures with the abdomen full, even though smaller than with the abdomen empty, and that CAPD treatment is a safe procedure in patients without complications.

In conclusion, we found that in patients with chronic renal failure treated with CAPD, the respiratory muscle strength was preserved but decreased significantly during CAPD. This decrease may have clinical significance in patients with pre-existing pulmonary diseases or severe uraemic lung conditions, but further studies are required to verify this probability. Finally, the results of this study clearly demonstrated an effect of the abdominal cavity on the mechanics of the respiratory muscles.

Acknowledgements: The authors wish to acknowledge ASTRA Greece, for supporting this investigation with a grant and N. Bizaki for typing the manuscript.

\section{References}

1. Bush A, Gabriel R. The lungs in uraemia: a review. $J$ $R$ Soc Med 1985; 78: 849-855.

2. Gibson DG. Haemodynamic factors in the development of acute pulmonary oedema in renal failure. Lancet 1966 ; ii: $1217-1220$.

3. Fairshter RD, Vaziri ND, Mirahmadi MK. Lung pathology in chronic hemodialysis patients. Int J Artif Organs 1982; 5: 99-102.

4. Nidus BD, Matalon R, Cantacuzino D, Eisinger RP. Uremic pleuritis: a clinicopathological entity. $N$ Engl J Med 1969; 281: 255-256.

5. Editorial. CAPD for chronic renal failure. Lancet 1980; 2 (8205): 1172-1173.

6. Gomez-Fernandez P, Sanchez Agudo L, Calatrava JM, et al. Respiratory muscle weakness in uremic patients under continuous ambulatory peritoneal dialysis. Nephron 1984; 36: 219-223.

7. Prezant DJ, Aldrich TK, Karpel JP, Lynn RI. Adaptations in the diaphragm's in vivo force-length relationship patients on continuous ambulatory peritoneal dialysis. Am Rev Respir Dis 1990; 141: 1342-1349.

8. Bush A, Miller J, Peacock AJ, Sopwith T, Gabriel R, Denison D. Some observations on the role of the abdomen in breathing in patients on peritoneal dialysis. Clin Sci 1985; 68: 401-406.

9. Rebuck AS. Peritoneal dialysis and the mechanics of the diaphragm. Perit Dial Bull 1982; 2: 109-110.

10. Popovich RP, Moncrief JW, Pyle WK. Transport Kinetics. In: Nolph KD, ed. Peritoneal Dialysis. 3rd edn. Boston, Kluwer Academic Publishers, 1990; pp. 96-113.

11. Cotes JE. In: Lung Function. 4th edn. Oxford, Blackwell, 1979; pp. 365-387.

12. Black LE, Hyatt RE. Maximal respiratory pressures: normal values and relationship to age and sex. Am Rev Respir Dis 1969; 99: 696-702.

13. Siafakas NM, Milona I, Salesiotou V, et al. Respiratory muscle strength in hypothyroidism. Chest 1992; 102: 189-194.

14. Bark H, Heimer D, Chaimovitz C, Mostoslovski M. Effect of chronic renal failure on respiratory muscle strength. Respiration 1988; 54: 153-161.

15. Arora NS, Rochester DE. Respiratory muscle strength and maximal voluntary ventilation in undernourished patients. Am Rev Respir Dis 1982; 126: 5-8.

16. Abelmann WH, Feank NR, Gaensler EA, Cugell DW. Effects of abdominal distension by ascites on lung volumes and ventilation. Arch Intern Med 1954; 93: 528-540.

17. Contreras G, Gutierrez M, Beroiza T, et al. Ventilatory drive and respiratory muscle function in pregnancy. Am Rev Respir Dis 1991; 144: 837-841.

18. Nava S, Zanotti E, Ambrosino N, Fracchia C, Scarabelli $\mathrm{C}$, Rampulla C. Evidence of acute diaphragmatic fatigue in a "natural" condition. Am Rev Respir Dis 1992; 146: 1226-1230. 